\section{Incidence, outcomes, and risk factors of pleural effusion in patients receiving dasatinib therapy for Philadelphia chromosome-positive leukemia}

\begin{abstract}
Timothy P. Hughes, ${ }^{1}$ Pierre Laneuville, ${ }^{2}$ Philippe Rousselot, ${ }^{3}$ David S. Snyder, ${ }^{4}$ Delphine Rea, ${ }^{5}$ Neil P. Shah, ${ }^{6}$ David Paar, ${ }^{7}$ Elisabetta Abruzzese, ${ }^{8}$ Andreas Hochhaus, ${ }^{9}$ Jeffrey H. Lipton ${ }^{10}$ and Jorge E. Cortes ${ }^{11}$

${ }^{1}$ Cancer Theme, SAHMRI, Division of Haematology, SA Pathology, University of Adelaide, South Australia, Australia; ${ }^{2}$ McGill University Health Centre, Montreal, QC, Canada; ${ }^{3}$ Hôpital Mignot, Université Versailles Saint-Quentin-en-Yvelines, Le Chesnay, France; ${ }^{4}$ City of Hope, Duarte, CA, USA; ${ }^{5}$ Service d'Hématologie Adulte, Hôpital Saint-Louis, Paris, France; ${ }^{\circ}$ UCSF School of Medicine, San Francisco, CA, USA; ${ }^{7 B}$ Bistol-Myers Squibb, Princeton, NJ, USA; ${ }^{8}$ Hematology, S. Eugenio Hospital, Tor Vergata University, Rome, Italy; ${ }^{~} \mathrm{Hematology/Oncology,} \mathrm{Universitätsklinikum} \mathrm{Jena,} \mathrm{Germany;}{ }^{10}$ Princess Margaret Cancer Centre, Toronto, ON, Canada and ${ }^{11}$ University of Texas MD Anderson Cancer Center, Houston, TX, USA
\end{abstract}

\section{Brerrata Storti Foundation}

Haematologica 2019

Volume 104(1):93-101

\section{ABSTRACT}

$\mathrm{D}$ asatinib, a second-generation BCR-ABL1 tyrosine kinase inhibitor, is approved for the treatment of chronic myeloid leukemia and Philadelphia chromosome-positive acute lymphoblastic leukemia, both as first-line therapy and after imatinib intolerance or resistance. While generally well tolerated, dasatinib has been associated with a higher risk for pleural effusions. Frequency, risk factors, and outcomes associated with pleural effusion were assessed in two phase 3 trials (DASISION and 034/Dose-optimization) and a pooled population of 11 trials that evaluated patients with chronic myeloid leukemia and Philadelphia chromosome-positive acute lymphoblastic leukemia treated with dasatinib (including DASISION and 034/Doseoptimization). In this largest assessment of patients across the dasatinib clinical trial program ( $\mathrm{N}=2712$ ), pleural effusion developed in $6-9 \%$ of patients at risk annually in DASISION, and in $5-15 \%$ of patients at risk annually in 034/Dose-optimization. With a minimum follow up of 5 and 7 years, drug-related pleural effusion occurred in $28 \%$ of patients in DASISION and in 33\% of patients in 034/Dose-optimization, respectively. A significant risk factor identified for developing pleural effusion by a multivariate analysis was age. We found that overall responses to dasatinib, progression-free survival, and overall survival were similar in patients who developed pleural effusion and in patients who did not. clinicaltrials.gov identifier 00481247; 00123474.

\section{Introduction}

Dasatinib is a potent second-generation BCR-ABL1 tyrosine kinase inhibitor (TKI) approved at $100 \mathrm{mg}$ once daily (OD) as first-line therapy in patients with chronic myeloid leukemia in chronic phase (CML-CP), and in patients with CML$\mathrm{CP}$ who are resistant to or intolerant of prior therapy. ${ }^{1}$ Dasatinib is also approved at $140 \mathrm{mg} \mathrm{OD}$ in patients with accelerated or blast phase CML (CML-AP/BP) or Philadelphia chromosome-positive acute lymphoblastic leukemia ( $\mathrm{Ph}^{+} \mathrm{ALL}$ ) with resistance to or intolerance of prior therapy. ${ }^{2-4}$

Although fluid retention has been associated with TKIs used to treat CML, pleural effusions, specifically with exudate characteristics, have been reported more commonly with dasatinib. ${ }^{1,5,6}$ The exact mechanisms behind treatment-related pleural effusion remain to be elucidated; however, it has been suggested that immune mechanisms may play a role, based on reports of association with lymphocytosis and the presence of lymphocyte-dominant exudates and chyle accumulate..$^{7-9}$ Alternatively, pleural effusion (with or without exudates) may also occur through inhibition of platelet-derived growth factor receptor- $\beta$ or SRC-family kinases. ${ }^{10,11}$ In

\section{Correspondence: \\ jcortes@mdanderson.org}

Received: January 18, 2018

Accepted: August 3, 2018.

Pre-published: August 9, 2018.

doi:10.3324/haematol.2018.188987

Check the online version for the most updated information on this article, online supplements, and information on authorship \& disclosures: www.haematologica.org/content/104/1/93

(C)2019 Ferrata Storti Foundation

Material published in Haematologica is covered by copyright. All rights are reserved to the Ferrata Storti Foundation. Use of published material is allowed under the following terms and conditions:

https://creativecommons.org/licenses/by-nc/4.0/legalcode. Copies of published material are allowed for personal or internal use. Sharing published material for non-commercial purposes is subject to the following conditions:

https://creativecommons.org/licenses/by-nc/4.0/legalcode, sect. 3. Reproducing and sharing published material for commercial purposes is not allowed without permission in writing from the publisher. 
Table 1. Summary of pleural effusion events in dasatinib-treated patients with CML-CP in DASISION and 034/Dose-optimization.

\begin{tabular}{|c|c|c|}
\hline & \multicolumn{2}{|c|}{ Dasatinib-treated patients, n (\%) } \\
\hline & $\begin{array}{l}\text { DASISION } \\
(n=258)\end{array}$ & $\begin{array}{c}\text { 034/Dose-optimization } \\
\text { (n=662) }\end{array}$ \\
\hline Patients with PE (any grade), $\mathrm{n}(\%)$ & $74(29)$ & $227(34)$ \\
\hline Patients with drug-related PE (any grade), n (\%) & $73(28)$ & $220(33)$ \\
\hline Grade 1 & $21(8)$ & $28(4)$ \\
\hline Grade 2 & $45(17)$ & $144(22)$ \\
\hline Grade 3 & $7(3)$ & $44(7)$ \\
\hline Grade 4 & 0 & $4(1)$ \\
\hline Patients with >1 drug-related PE (any grade), n (\%) & $45(17)$ & $134(20)$ \\
\hline Median time to first drug-related PE (any grade), weeks (range) & $114(4-299)$ & $60(1-371)$ \\
\hline Grade 1 & $132(4-299)$ & $60(2-369)$ \\
\hline Grade 2 & $114(6-281)$ & $83(1-371)$ \\
\hline Grade 3 & $175(114-274)$ & $105(3-350)$ \\
\hline Median duration of first drug-related PE (any grade), weeks (range) & $4(0-223)$ & $4(0-235)$ \\
\hline Grade 1 & $7(1-223)$ & $7(0-80)$ \\
\hline Grade 2 & $3(1-210)$ & $3(0-235)$ \\
\hline Grade 3 & $4(0-25)$ & $3(0-96)$ \\
\hline \multicolumn{3}{|l|}{ First occurrences of PE (any grade) by patients at risk, $\mathrm{n} / \mathrm{n}$ at risk (\%)* } \\
\hline Year 1 & $20 / 258(8)$ & 100/662 (15) \\
\hline Year 2 & $13 / 209(6)$ & $37 / 430(9)$ \\
\hline Year 3 & $11 / 184(6)$ & $30 / 305(10)$ \\
\hline Year 4 & $14 / 160(9)$ & $15 / 230(7)$ \\
\hline Year 5 & 12/141 (9) & $17 / 182(9)$ \\
\hline Year 6 & NA & $7 / 144(5)$ \\
\hline Year 7 & NA & $9 / 133(7)$ \\
\hline
\end{tabular}

${ }^{*}$ Two patients in 034/Dose-optimization have not been categorized into any year due to missing PE onset date. CML-CP: chronic myeloid leukemia in chronic phase; NA: no applicable; PE: pleural effusion.

clinical practice, pleural effusion observed with dasatinib therapy remains a concern for both patients and prescribers.

Risk factors for pleural effusion in dasatinib-treated patients have been described in previous reports, including advanced age, advanced disease, heart disease, preexisting hypertension, hypercholesterolemia, autoimmune disease, rash, drug dose and schedule, and the presence of lymphocytosis. ${ }^{10,12-14}$ A correlation with plasma trough level, drug exposure, treatment duration, and depth of response to treatment has been suggested, but not confirmed. ${ }^{15}$

Here, we present an analysis of the proportion of patients with pleural effusion by grade, and efficacy outcomes in these patients, in dasatinib clinical trials. Additionally, we report the results of multivariate analyses of dasatinib clinical trial data, exploring factors associated with the development of pleural effusion in dasatinibtreated patients.

\section{Methods}

\section{Patient populations}

DASISION (CA180-056). In the phase 3 dasatinib versus imatinib study in treatment-naive CML patients (DASISION [CA180056]; clinicaltrials.gov identifier 00481247), 519 patients with newly diagnosed CML-CP were randomized to receive either $100 \mathrm{mg}$ $\mathrm{QD}$ dasatinib $(\mathrm{n}=259)$ or $400 \mathrm{mg} \mathrm{QD}$ imatinib $(\mathrm{n}=260){ }^{16-18}$ The pri- mary endpoint was the proportion of patients with confirmed complete cytogenetic responses (CCyR) by 12 months. Patients included in this report had a minimum of 5 years of follow up. ${ }^{19}$

034/Dose-optimization (CA180-034). In the phase 3 dose-optimization study in imatinib-resistant or -intolerant CML-CP patients (CA180-034; clinicaltrials.gov identifier 00123474), 670 patients with CML-CP intolerant of or resistant to imatinib were randomized to receive dasatinib $100 \mathrm{mg} \mathrm{OD}(\mathrm{n}=167), 140 \mathrm{mg} \mathrm{OD}(\mathrm{n}=167), 50 \mathrm{mg}$ twice daily (BID; $n=168)$, or $70 \mathrm{mg}$ BID $(\mathrm{n}=168))^{20.22} \mathrm{~A}$ subset of patients modified their dose over the course of the study; however, analyses of data were performed according to each patient's initial randomization. The primary endpoint was the percentage of patients with major cytogenetic response (MCyR) after a minimum follow up of 6 months. Patients included in this report had a minimum of 7 years of follow up. ${ }^{23}$

Pooled population of patients with $\mathrm{Ph}^{+}$leukemia. Patients $(\mathrm{N}=2712)$ with $\mathrm{Ph}^{+}$leukemia who were treated with first- or second-line dasatinib $15 \mathrm{mg}$ to $240 \mathrm{mg} \mathrm{OD}$ in 1 of 11 phase 1, 2, or 3 trials were included in these analyses (Online Supplementary Table S1). ${ }^{16,19,21,23-31}$ DASISION and 034/Dose-optimization were analyzed separately and as part of the pooled population for this report. In total, 324 newly diagnosed patients treated with dasatinib $100 \mathrm{mg}$ OD (DASISION [n=258], CA180-363 [ $\mathrm{n}=66$ ]), and 2388 patients with CML (CML-CP [ $\mathrm{n}=1294]$, advanced phases of CML [ $\mathrm{n}=958])$ or $\mathrm{Ph}^{+} \mathrm{ALL}(\mathrm{n}=136)$ previously treated with imatinib were included. Previously treated patients received dasatinib at daily doses ranging from $15 \mathrm{mg}$ to $240 \mathrm{mg}$ administered once or in divided doses daily. 


\section{Assessments}

Pleural effusions were monitored continuously in treated patients who received at least 1 dose of study drug (DASISION $[\mathrm{n}=258]$, 034/Dose-optimization $[\mathrm{n}=662]$, pooled population $[n=2712])$. Pleural effusion by first onset is presented by year for patients at risk (the number of patients who were treated within a year and did not have pleural effusion). Effusions were graded according to the Common Terminology Criteria for Adverse

A

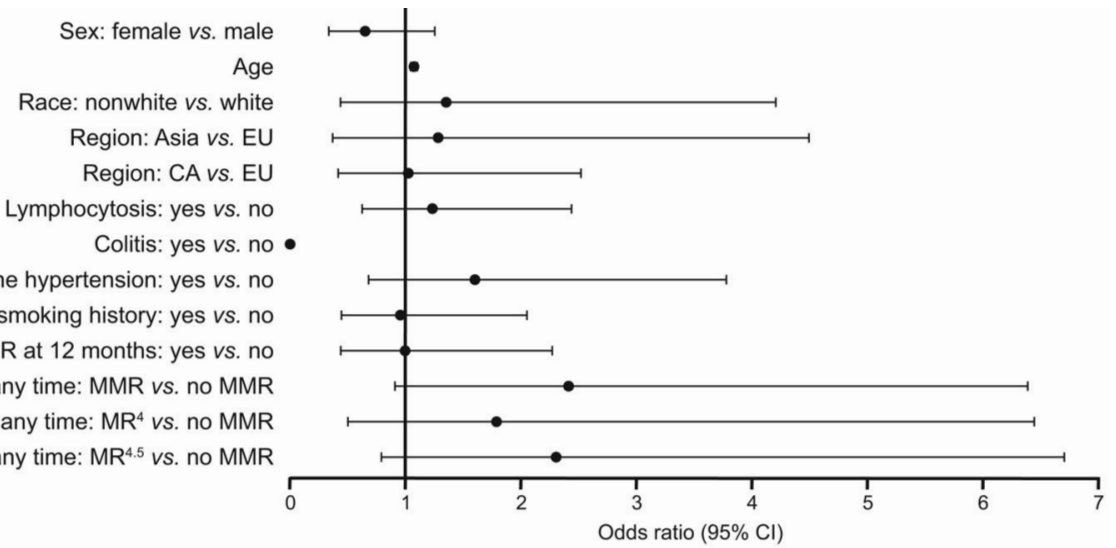

B

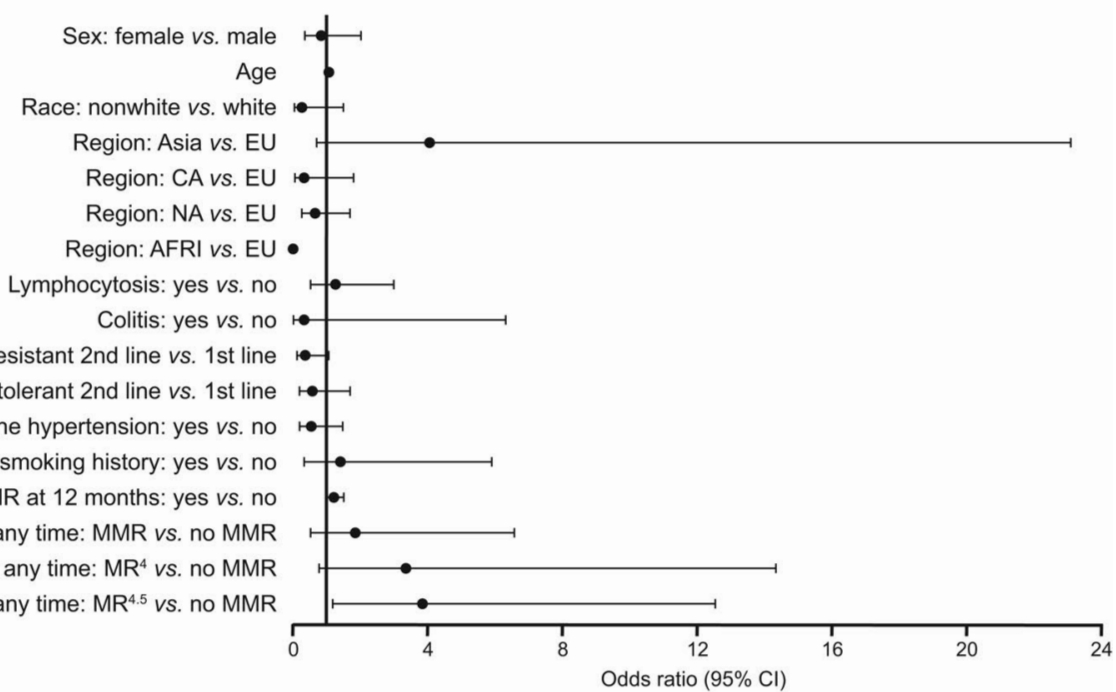

C

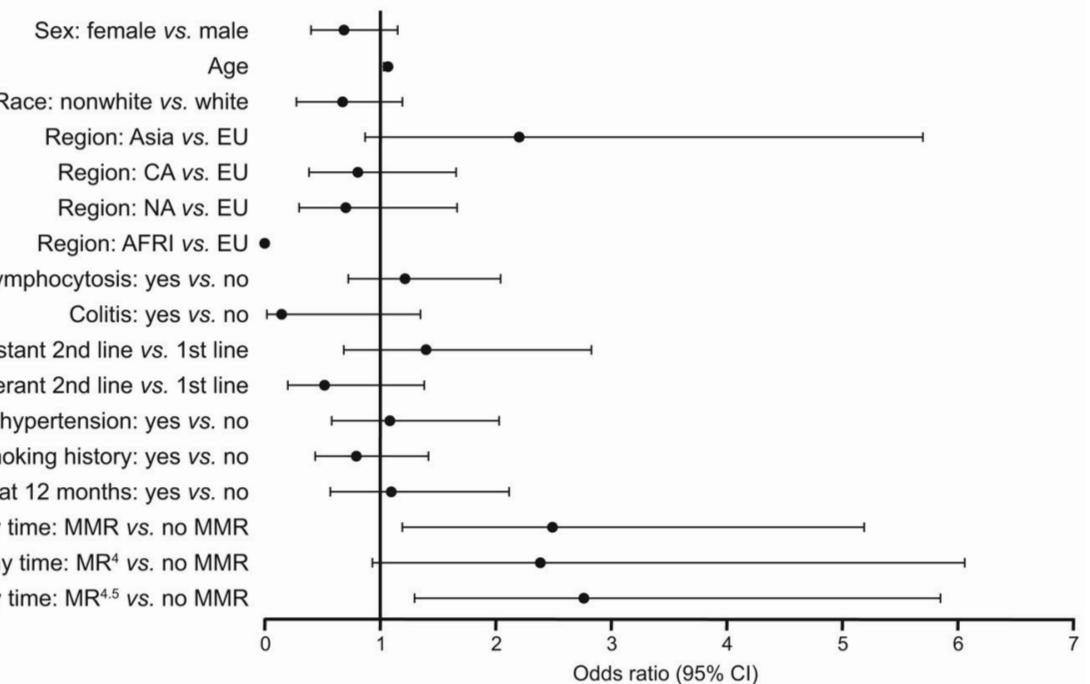

Figure 1. Retrospective multivariate analysis to determine if there was an association between pleural effusion and potential risk factors. Odds ratios (ORs) with $95 \%$ confidence intervals (Cls) are shown for potential predictive variables listed for patients with CML-CP treated with 100 mg QD dasatinib from DASISION (A), 034/Dose-optimization (B), or both DASISION and 034/Dose-optimization (C). AFRI: Africa; CA: Caribbean; CML-CP: chronic myeloid leukemia in chronic phase; EU: European Union; MMR: major molecular response, $B C R-A B L 1$ transcripts $\leq 0.1 \%$ on the International Scale (IS) corresponding to a 3-log reduction from a standardized baseline; MR : BCR-ABL1 transcripts $<0.01 \%$ (IS) corresponding to a 4-log reduction from a standardized baseline; MR ${ }^{4.5}$ : BCR-ABL1 transcripts $\leq 0.0032 \%$ (IS) corresponding to a 4.5-log reduction from a standardized baseline; NA: North America; PE: pleural effusion; QD: once daily. 
Table 2. Hypertension by occurrence of drug-related pleural effusion in dasatinib-treated patients with CML-CP in DASISION and 034/Dose-optimization.

\begin{tabular}{lcc} 
& $\begin{array}{c}\text { Dasatinib-treated patients, n (\%) } \\
\text { 034/ Dose-0ptimization } \\
(\mathbf{n = 6 6 2})\end{array}$ & $61(9)$ \\
DASISION & $28(1=258)$ & $24(39)$ \\
Patients with baseline hypertension & $28(11)$ & $37(61)$ \\
With PE & $13(46)$ & $40(66)$ \\
Without PE & $15(54)$ & $18(45)$ \\
With anti-hypertensive medication & $20(71)$ & $22(55)$ \\
With PE & $9(45)$ & $21(34)$ \\
Without PE & $11(55)$ & $6(29)$ \\
Without anti-hypertensive medication & $8(29)$ & $15(71)$ \\
With PE & $4(50)$ & $601(91)$ \\
Without PE & $4(50)$ & $196(33)$ \\
Patients without baseline hypertension & $230(89)$ & $405(67)$ \\
With PE & $60(26)$ & \\
Without PE & $170(74)$ & \\
\hline
\end{tabular}

CML-CP: chronic myeloid leukemia in chronic phase; PE: pleural effusion.

Table 3. Age by occurrence of drug-related pleural effusion in dasatinib-treated patients with CML-CP in DASISION and 034/Dose-optimization.

\begin{tabular}{lcccc}
\hline Age, years & $\begin{array}{c}\text { DASISION (n=258) } \\
\text { No PE } \\
(n=185)\end{array}$ & $\begin{array}{c}\text { With PE } \\
(n=73)\end{array}$ & $\begin{array}{c}\text { No PE } / \text { Dose-0ptimization }(n=662) \\
(n=442)\end{array}$ & $\begin{array}{c}\text { With PE } \\
(n=220)\end{array}$ \\
Mean (standard deviation) & $43(14)$ & $55(13)$ & $52(15)$ & $58(13)$ \\
$95 \%$ CI (mean) & $(41-45)$ & $(52-58)$ & $(50-53)$ & $(57-60)$ \\
Median (range) & $41(18-84)$ & $56(24-82)$ & $53(18-84)$ & $60(22-84)$ \\
$95 \%$ CI (median) & $(41-45)$ & $(52-58)$ & $(50-53)$ & $(57-60)$
\end{tabular}

CI: confidence interval; CML-CP: chronic myeloid leukemia in chronic phase; PE: pleural effusion.

Events Version $3.0^{32}$ in DASISION and 034/Dose-optimization. Additional description of assessments and statistical analyses can be found in the Online Supplementary Material.

Each study protocol was approved by all institutional review boards, ethics committees, and national competent authorities at participating sites.

\section{Results}

\section{Incidence of pleural effusion}

$D A S I S I O N$. With a minimum of 5 years of follow up, 73 (28\%) patients in DASISION reported drug-related pleural effusion (Table 1). One case of pleural effusion was not attributed to dasatinib by the investigator (Grade 2) and occurred $>30$ days after the last study dose was given. Most drug-related pleural effusions were Grade $1(8 \%)$ or Grade $2(17 \%)$, and no Grade 4 events were reported. The median duration of all first cases of drug-related pleural effusion was 4 weeks. The median daily dose of dasatinib for patients who developed drug-related pleural effusion was $100 \mathrm{mg}$, similar to the overall dasatinib-treated population. ${ }^{19}$

New cases of pleural effusion (any grade) occurred in $8 \%$ of patients receiving dasatinib in the first year of the study, and $6-9 \%$ each remaining year up to 5 years, suggesting a steady but continuous risk over time (Table 1). The proportion of patients with a recurrent $(>1)$ drug- related pleural effusion (any grade) was $62 \%(n=45 / 73)$. Of these, 16 patients had 2 separate events, 6 had 3 separate events, 4 had 4 separate events, and 19 had $\geq 5$ separate events. Twelve patients discontinued due to recurrent pleural effusion. Of these patients, 9 had $\geq 3$ recurring events. Dose interruptions and dose reductions due to pleural effusion occurred in $62 \%$ and $41 \%$ of patients, respectively.

034/Dose-optimization. With a minimum follow up of 7 years, drug-related pleural effusion (any grade) occurred in $33 \%$ of patients (Table 1). Although the median dose of dasatinib for patients with drug-related pleural effusion (any grade) was $100 \mathrm{mg}$ daily (range $0-180 \mathrm{mg}$ ), pleural effusion rates varied across dosing groups in 034/Doseoptimization, with $28 \%(n=46 / 165)$ of patients experiencing any-grade pleural effusion in the $100 \mathrm{mg} \mathrm{OD}$ group and $35 \%(n=174 / 497)$ in the other groups. The median duration of first pleural effusion was 4 weeks. The majority of drug-related pleural effusions were Grade 1/2, and Grade 3/4 drug-related pleural effusions were reported in $48(7 \%)$ patients in the total treated population. Of these, 8 occurred in the $100 \mathrm{mg} \mathrm{QD}$ group and 40 in the remaining groups. First occurrences of pleural effusion (any grade) occurred in $15 \%$ of dasatinib-treated patients in the first year of the study, and in $5-10 \%$ per year up to 7 years. Recurrent $(>1)$ drug-related pleural effusion (any grade) occurred in $61 \%(n=134 / 220)$. Of these, 54 patients had 2 separate events, 31 had 3 separate events, 16 had 4 sepa- 
rate events, and 33 had $\geq 5$ separate events. In all 034/Dose-optimization dose groups, discontinuation due to recurrent pleural effusion occurred in $46(7 \%)$ patients.

The cumulative incidence rate of pleural effusion was lower in the $100 \mathrm{mg} \mathrm{OD}$ group than in dose groups and increased over time (at 2 years $15 \%$ vs. $24 \%$, respectively; at 7 years $27 \%$ vs. $36 \%$, respectively). Similarly, the cumulative incidence rate of Grade 3/4 pleural effusion was lower in the $100 \mathrm{mg} \mathrm{OD}$ group than in the other dose groups (at 7 years 5\% vs. 9\%, respectively), and increased over time (at 2 years $2 \%$ vs. $4 \%$, respectively; at 5 years $4 \%$ vs. $7 \%$, respectively). Within year 7 of the study, new cases of pleural effusion occurred in 5\% (2/42) of patients at risk treated with dasatinib $100 \mathrm{mg} \mathrm{OD}$ and in $8 \%(7 / 91)$ of patients at risk in the other treatment arms. The cumulative rates of drug-related pleural effusion over time for the $100 \mathrm{mg} \mathrm{OD}$ arm were $14 \%$ at 2 years, $24 \%$ at 5 years, and $28 \%$ at 7 years. For the other treatment arms, the cumulative rates of drug-related pleural effusion over time were $24 \%$ at 2 years, $32 \%$ at 5 years, and $35 \%$ at 7 years.

The incidence of pleural effusion was also lower in imatinib-intolerant and imatinib-resistant patients receiving $100 \mathrm{mg}$ OD than in the other dose groups. Pleural effusion (any grade) was reported in 19\% of patients who were imatinib-intolerant in the $100 \mathrm{mg} \mathrm{OD}$ arm and in $43 \%$ of imatinib-intolerant patients in the other dose groups, while pleural effusion (any grade) was reported in $31 \%$ of imatinib-resistant patients in the $100 \mathrm{mg} \mathrm{OD}$ arm and in $35 \%$ in the other dose groups. Pleural effusions were managed with dose interruptions in $44 \%$ of patients.

Pooled population of patients with $\mathrm{Ph}^{+}$leukemia. Eleven dasatinib clinical trials of patients with $\mathrm{Ph}^{+}$leukemia, including the DASISION and 034/Dose-optimization trials, were pooled for this analysis to include the largest number of dasatinib-treated patients possible. Pleural effusion of any grade from any cause occurred in 946 patients (35\%), 553 (34\%) with CML-CP and 393 (36\%) with CML-AP/BP or $\mathrm{Ph}^{+}$ALL. Grade $3 / 4$ pleural effusions were reported in $223(8.2 \%)$ patients, $119(7 \%)$ with CML-CP, and $104(10 \%)$ with CML-AP/BP or $\mathrm{Ph}^{+} \mathrm{ALL}$. Deaths due to pleural effusion were reported in $5(<1 \%)$ patients, all with CML-AP/BP or $\mathrm{Ph}^{+} \mathrm{ALL}$ (4 were not receiving the currently approved dose of $140 \mathrm{mg} \mathrm{OD}$ dasatinib $\left.{ }^{1}\right)$. Drugrelated pleural effusion of any grade occurred in 538 (33\%) patients with CML-CP and 345 (32\%) with CML-AP/BP or $\mathrm{Ph}^{+} \mathrm{ALL}$ (883 [33\%] patients total). Grade 3/4 drugrelated pleural effusion episodes were reported in 114 (7\%) patients with CML-CP and 93 (9\%) patients with CML-AP/BP or $\mathrm{Ph}^{+}$ALL (207 [8\%] patients in total). One drug-related death was reported $(<1 \%)$ in a patient with $\mathrm{CML}-\mathrm{AP} / \mathrm{BP}$ or $\mathrm{Ph}^{+} \mathrm{ALL}$.

\section{Risk factors for pleural effusion}

Based on risk factors for pleural effusion in dasatinibtreated patients described in literature, ${ }^{9,11-13}$ retrospective multivariate analyses were performed to investigate the association between pleural effusion and baseline hypertension, age, and lymphocytosis in patients treated with dasatinib, as well as additional variables of interest including sex, region, dosing schedule (034/Dose-optimization only), baseline Euro (Hasford) risk scores (DASISION only), exposure to interferon alpha (034/Dose-optimization only), $B C R-A B L 1$ levels, baseline parameters, major molecular response (MMR) at 12 months, line of therapy, duration of prior TKI therapy, and depth of MR at any time. Average daily dose, prior skin rash, and prior autoimmune or lung disease were assessed in the DASISION/034/Dose-optimization pooled population only.

DASISION. In DASISION, 28 (11\%) patients had hypertension, and 13 of 28 (46\%) patients with hypertension developed drug-related pleural effusion (Table 2). Of the 13 patients who developed pleural effusion, 9 were taking antihypertensive medications. When the relation between hypertension and pleural effusion was assessed in a multivariate analysis, there was no significant association found (Figure 1A). Pulmonary hypertension was reported in $14(5 \%)$ dasatinib-treated patients, 9 of whom had pleural effusion. One patient with pulmonary hypertension underwent right heart catheterization in order to confirm pulmonary arterial hypertension (PAH); however, the procedure did not support a diagnosis of PAH. Twelve of the 14 pulmonary hypertension diagnoses were drug related. ${ }^{19}$ In DASISION, the correlation between pulmonary hypertension and pleural effusion was not confirmed.

The median age of patients who developed drug-related pleural effusion in DASISION was 56 years, whereas for patients who did not develop pleural effusions it was 41 years (Table 3 ). Of significance, older age was found to be a risk factor for developing pleural effusion (odds ratio [OR] 1.067; 95\% confidence interval [CI] 1.041-1.094; Figure $1 \mathrm{~A})$. These results were confirmed using a reduced model multivariate analysis.

In DASISION, 29 (11\%) patients had lymphocytosis at any time prior to pleural effusion, and 0 patients developed lymphocytosis after. However, lymphocytosis was not found to be a significant risk factor for the development of pleural effusion by multivariate analysis (Figure 1A).

Of the patients receiving $100 \mathrm{mg} \mathrm{OD}$ dasatinib in the DASISION trial, 86 (33\%) patients had low-risk Euro scores, 124 (48\%) had intermediate-risk Euro scores, and $49(19 \%)$ had high-risk Euro scores. ${ }^{16}$ Using a reduced model multivariate analysis, patients with intermediaterisk Euro scores were not found to be at an increased risk of developing pleural effusion compared with patients with low-risk Euro scores. Similarly, no association was observed between pleural effusion and patients with highrisk Euro scores compared with patients with low-risk Euro scores.

The remaining variables investigated via multivariate analysis were found not to have an association with pleural effusion (Figure 1A).

034/Dose-optimization. Similar to DASISION, no significant association between pleural effusion and hypertension was found for patients in 034/Dose-optimization treated with dasatinib $100 \mathrm{mg} \mathrm{OD}$, the currently approved dose for CML-CP ${ }^{1}$ (Figure 1B). Twenty-four of 61 (39\%) patients from any treatment arm with hypertension developed drug-related pleural effusion (Table 2). Of these 24 patients, 18 were taking antihypertensive medication. Pulmonary hypertension (any grade) was reported in 3 $(2 \%)$ patients in the $100 \mathrm{mg}$ OD dose group and in 13 $(3 \%)$ patients in the other dose groups. ${ }^{23}$ One patient $(<1 \%)$ in the $100 \mathrm{mg}$ QD dose group reported severe drugrelated $\mathrm{PAH}$, confirmed with a right heart catheterization procedure. $^{23}$ Similar to DASISION, the association between pulmonary hypertension and pleural effusion was not confirmed in these patients.

In 034/Dose-optimization, the median age of all patients who developed drug-related pleural effusion was 
Table 4. Efficacy of dasatinib by occurrence of drug-related pleural effusion in dasatinib-treated patients with CML-CP in DASISION and 034/Dose-optimization.

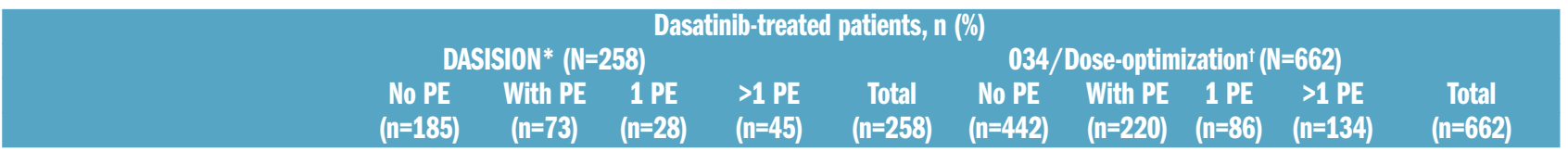

Best response to dasatinib

\begin{tabular}{|c|c|c|c|c|c|c|c|c|c|c|}
\hline \multirow{2}{*}{ MMR } & 138 & 60 & 24 & 36 & 198 & 162 & 117 & 37 & 80 & 279 \\
\hline & (75) & (82) & (86) & (80) & (77) & (37) & (53) & $(43)$ & $(60)$ & (42) \\
\hline \multirow[t]{2}{*}{$\mathrm{MR}^{4.5}$} & 78 & 37 & NA & NA & 115 & 57 & 40 & $\mathrm{NA}$ & NA & 97 \\
\hline & (42) & (51) & & & (45) & (13) & (18) & & & (15) \\
\hline \multirow[t]{2}{*}{ CCyR } & 155 & 71 & NA & $\mathrm{NA}$ & 226 & 193 & 146 & $\mathrm{NA}$ & $\mathrm{NA}$ & 339 \\
\hline & (84) & (97) & & & (88) & (44) & (66) & & & (51) \\
\hline $\begin{array}{l}\text { Median MMR duration, } \\
\text { months (range) }\end{array}$ & NA & NA & $\begin{array}{c}39 \\
(0-68)\end{array}$ & $\begin{array}{c}45 \\
(0-70)\end{array}$ & $\begin{array}{c}48 \\
(0-70)\end{array}$ & $\mathrm{NA}$ & $\mathrm{NA}$ & $\begin{array}{c}34 \\
(0-85)\end{array}$ & $\begin{array}{c}42 \\
(0-84)\end{array}$ & $\begin{array}{c}43 \\
(0-90)\end{array}$ \\
\hline
\end{tabular}

*Both on-study and follow-up patients are included. 'Only on-study patients are included. ${ }^{*}$ All responses listed were those obtained at end of study. For DASISION, that was 60 months, and for 034/Dose-optimization, that was 84 months. CCyR: complete cytogenetic response; CML-CP: chronic myeloid leukemia in chronic phase; MMR: major molecular response, $B C R-A B L 1$ transcripts $\leq 0.1 \%$ on the International Scale (IS) corresponding to a 3-log reduction from the standardized baseline; MR ${ }^{4.5}: B C R-A B L 1$ transcripts $\leq 0.0032 \%$ (IS) corresponding to a 4.5-log reduction from the standardized baseline; NA: not applicable; PE: pleural effusion.

60 years; patients who did not develop pleural effusion had a median age of 53 years (Table 3 ). Advanced age was found to be a significant risk factor for pleural effusion in patients treated with $100 \mathrm{mg} \mathrm{OD}$ dasatinib in a multivariate model (OR 1.074; 95\% CI 1.035-1.114; Figure 1B). In addition to age, a strong statistical correlation was observed between the depth of MR and the overall incidence of pleural effusion, for those treated with $100 \mathrm{mg}$ OD dasatinib (OR 3.851; 95\% CI 1.182-12.552) (Figure $1 B)$. Both age and depth of MR were confirmed as risk factors by a reduced model multivariate analysis.

Lymphocytosis was not found to be associated with the development of pleural effusion in a multivariate analysis of patients treated with $100 \mathrm{mg}$ OD dasatinib (Figure 1B); overall, $17(10 \%)$ patients had lymphocytosis before the onset of pleural effusion versus 0 after.

No other associations were found between pleural effusion and the remaining variables analyzed via multivariate analysis (Figure 1B).

Pooled DASISION and 034/Dose-optimization. To assess the relation between potential prognostic factors and pleural effusion in a larger population, patients treated with $100 \mathrm{mg}$ OD dasatinib from both DASISION ( $\mathrm{n}=258)$ and $034 /$ Dose-optimization $(n=165)$ were pooled $(n=423)$, and a multivariate analysis was performed (Figure 1C). In this pooled population, patients in MMR (OR 2.482; 95\% CI 1.191-5.174) and $M^{4.5}$ (OR 2.756; 95\% CI 1.30-5.841) had a significantly increased risk of developing pleural effusion compared with patients not in MMR. Increased age also was found to be a significant risk factor (OR 1.069; 95\% CI 1.048-1.091).

In the pooled DASISION and 034/Dose-optimization patient population, 40 (9\%) patients had a history of lung disease, and $13(3 \%)$ patients had a history of autoimmune disease. When the relationship between pleural effusion and prior lung disease, autoimmune disease, or skin rash was assessed using a reduced model multivariate analysis, no association was found. Average daily dasatinib dose also was not found to be a risk factor using the reduced model.

In the reduced multivariate model, imatinib-intolerant patients receiving second-line dasatinib had a significantly increased risk of developing pleural effusion compared with first-line patients (OR 0.232; 95\% CI 0.086-0.623).

\section{Efficacy of patients with pleural effusion}

DASISION. Of 73 dasatinib-treated patients in the DASISION trial with drug-related pleural effusion, $97 \%$ achieved CCyR, $82 \%$ had MMR, and $51 \%$ had $M^{4.5}$ (Table 4). These results are comparable to those in patients who did not have drug-related pleural effusion, and reflective of the overall responses for the entire study population. ${ }^{17}$ Duration of MMR was 39 months for those with 1 drug-related pleural effusion and 45 months for those with $>1$ (Table 4). Five-year progression-free survival (PFS) was similar for patients with or without drug-related pleural effusion (Online Supplementary Figure S1A). Of patients who experienced drug-related pleural effusion events, $5 / 73(7 \%)$ progressed, whereas 21/185 (11\%) patients who did not experience pleural effusion events progressed. Overall survival (OS) was similar in patients who did or did not experience drug-related pleural effusion as well (Online Supplementary Figure S1B).

Many patients did achieve cytogenetic or molecular responses prior to the first occurrence of drug-related pleural effusion, and these responses were often maintained or improved despite dose modifications required to manage the effusion (Online Supplementary Table S2). Sixty-five patients $(89 \%$ of patients with a drug-related pleural effusion) had CCyR, 35 (48\%) had MMR, and 12 (16\%) had $M R^{4.5}$ prior to experiencing their first pleural effusion event. Following the first pleural effusion, 55 patients maintained/improved to CCyR. Similarly, 19 patients maintained/improved to MMR, and 32 patients maintained/improved to $\mathrm{MR}^{4.5}$. One patient went from $M M R$ to $B C R-A B L 1 \quad 0.1-\leq 1 \%$ following their first pleural effusion event. No patient had $B C R-A B L 1>10 \%$ or lost any cytogenetic response after their first event.

034/Dose-optimization. Of 220 dasatinib-treated patients in 034/Dose-optimization who had drug-related pleural effusion, $66 \%$ achieved CCyR, 53\% had MMR, and $18 \%$ had $\mathrm{MR}^{4.5}$ (Table 4). As seen in the DASISION trial, molec- 
ular responses in the 034/Dose-optimization trial for patients who had drug-related pleural effusion events versus patients who did not were similar, although a trend showed slightly higher molecular responses for those who experienced pleural effusions. The duration of MMR was 34 months for those with 1 drug-related pleural effusion, and 42 months for those with $>1$ (Table 4). At the end of the 034/Dose-optimization 7-year study, PFS for dasatinib-treated patients who experienced drug-related pleural effusion events was similar to PFS for patients who did not experience effusion events (Online Supplementary Figure S2A). Among patients who had drug-related pleural effusion, 93/220 (42\%) progressed, compared with $220 / 442(50 \%)$ patients who did not have pleural effusion but did progress. Seven-year OS in 034/Dose-optimization was similar across patients with and without drugrelated pleural effusion (Online Supplementary Figure S2B).

As seen in DASISION, patients in 034/Dose-optimization were able to achieve responses prior to their first event, and these responses were maintained or improved following the pleural effusion in some patients (Online Supplementary Table S3). One hundred and sixteen patients (53\% of patients with a drug-related pleural effusion evaluable for efficacy endpoints) had CCyR, 66 (30\%) had $M M R$, and $15(7 \%)$ had $M R^{4.5}$ prior to experiencing a first case of pleural effusion. Following the effusion, 55 patients maintained or improved to CCyR and 9 patients lost CCyR. Changes in the depth of molecular response were also similar: 55 patients maintained/improved to $\mathrm{MMR}$, and 31 patients maintained/improved to $\mathrm{MR}^{4.5}$. Three patients went from MMR to $B C R-A B L 1 \quad 0.1-\leq 1 \%$ following their first pleural effusion event. Of these patients, all had $B C R-A B L 1>0.1 \%$ after their first event. Two patients in 034/Dose-optimization were excluded from the efficacy analysis because the date of onset of pleural effusion was not captured.

\section{Discussion}

Pleural effusion has been reported in dasatinib-treated patients at any time during the course of treatment, though the severity is generally mild to moderate. Grade 1 effusions are often asymptomatic and may not have been picked up in the absence of routine chest X-rays (only required in the DASISION trial), potentially reducing the incidence of clinically significant effusions in this patient population. However, we cannot comment that Grade 1 pleural effusions would not progress with time. The risk of pleural effusion remains even after long-term dasatinib treatment in effusion-naive patients; thus, maintaining awareness of the risk is important.

As fluid retention events have been reported with most BCR-ABL1-targeted TKIs, it is tempting to attribute the occurrence of pleural effusion to a class effect on fluid overload. However, an immune-mediated mechanism is more likely for dasatinib-related pleural effusion, as exudate containing high lymphocyte counts (predominantly natural killer cells) and chyle accumulate have been reported in pleural fluids and tissue from patients on dasatinib. ${ }^{15,33,34}$ Pleural effusion developed slightly more often in patients with lymphocytosis than in patients without lymphocytosis (33\% with lymphocytosis vs. 26\% without lymphocytosis) in the DASISION trial, although this difference was not statistically significant. ${ }^{35}$ We found that lymphocytosis occurred during therapy, which appears to represent a risk factor for pleural effusion because it preceded pleural effusion events.

Through multivariate analyses, we determined that race, sex, region, exposure to interferon, $B C R-A B L 1$ levels at 3 months, lymphocytosis, colitis, history of autoimmune disease, history of lung disease, history of skin rash, baseline smoking history, MMR at 12 months, average daily dose, line of therapy, baseline Euro risk scores, and duration of prior TKI therapy were not associated with an increased risk of pleural effusion. Other risk factors for pleural effusion previously described include advanced disease, heart disease, and hypercholesterolemia. ${ }^{10,12-14}$ It is difficult to analyze the association between the incidence of pleural effusion and the depth of molecular response achieved without correcting for the time of dasatinib exposure, given that most patients achieving deep molecular responses are typically on dasatinib longer and would therefore be expected to have a greater risk of developing pleural effusion. To address this, we evaluated MMR at 12 months as a potential risk factor; however, no association was observed. We found second-line patients with previous intolerance of imatinib to be at an increased risk of developing pleural effusion compared with first-line patients, although no association was observed for second-line imatinib-resistant patients. Finally, although effusions can develop in adults at any age, we determined that advanced age was the only significant patient risk factor for pleural effusion, particularly in those treated with $100 \mathrm{mg} /$ day of dasatinib. Additional potential risk factors, such as a history of hypertension, can develop during treatment with dasatinib, and should be considered when evaluating individual patients, though the association between pleural effusion and hypertension was not substantiated in this analysis.

Dasatinib dose, as a potential risk factor for pleural effusion, is of special interest. Wang et al. noted that pleural effusion was associated with trough drug concentrations, indicating that dasatinib pharmacokinetics may play a role in the development of pleural effusion. ${ }^{13}$ We did not find dasatinib dose to be a risk factor for the development of pleural effusion in the pooled population of patients initially treated with $100 \mathrm{mg}$ OD dasatinib. However, since patients with advanced disease in the pooled population of dasatinib-treated patients with $\mathrm{Ph}^{+}$leukemia described here were treated with higher doses of dasatinib (up to 240 mg daily) than patients with CML-CP, dasatinib dose may still be associated with the increased rate of Grade 3/4 pleural effusions observed. Also, we reported that pleural effusion (any grade) was observed in a lower percentage of patients in the $100 \mathrm{mg} \mathrm{OD}$ arm versus the other dose groups in 034/Dose-optimization. A retrospective study evaluating the toxicity-guided administration of a reduced-dose dasatinib regimen in similar imatinib-resistant/intolerant patients revealed that on/off treatment significantly reduced pleural effusions. ${ }^{36}$ Furthermore, recent sub-analyses of DASISION revealed that dose reductions for adverse events, including pleural effusion, did not affect dasatinib efficacy, ${ }^{37,38}$ suggesting that it may be possible to administer lower doses to populations at higher risk for pleural effusion development. Moreover, we found that the achievement of MMR and $M R^{4.5}$ was found to be correlated with a higher risk of developing pleural effusion. This may be because patients without MMR may have discontinued dasatinib treatment earlier than 
those with a response. This supports a hypothesis that pleural effusion may be a marker for longevity of treatment: As patients do well on dasatinib and remain on treatment longer, they may be more likely to develop a pleural effusion. Further investigation into the relation between duration of treatment and pleural effusion is warranted.

Clinical data on molecular responses for patients who experienced pleural effusions during treatment with dasatinib are limited, though our observations indicate that patients who experienced pleural effusions while on dasatinib had similar responses to treatment as those who did not develop pleural effusion. A retrospective study examining dasatinib-related pleural effusion in CML patients across 21 hematologic centers in Italy revealed that at the time of the first effusion, $28.6 \%$ were in MMR and $37.8 \%$ were in $\mathrm{MR}^{4.5} .{ }^{39}$

In summary, pleural effusion is an adverse event seen disproportionately in patients treated with dasatinib; however, the management of pleural effusion by dose reductions does not negatively affect the response rate to dasatinib. Advanced age and longevity of treatment were found to be predictive risk factors for the development of pleural effusion.

\section{Acknowledgments}

The authors would like to thank the patients and families for making these Bristol-Myers Squibb-sponsored trials possible.

\section{Funding}

This analysis was supported by funding from Bristol-Myers Squibb. The Bristol-Myers Squibb policy on data sharing may be found at: https://www.bms.com/researchers-andpartners/independent-research/data-sharing-requestprocess.html. Professional medical writing and editorial assistance was provided by Samantha L. Dwyer, PhD, and Jessica Franciosi, PhD, of StemScientific, an Ashfield Company, part of UDG Healthcare plc, funded by Bristol-Myers Squibb.

\section{References}

1. Sprycel (dasatinib) [prescribing information]. Princeton, NJ: Bristol-Myers Squibb Company; 2017.

2. Kantarjian H, Cortes J, Kim DW, et al. Phase 3 study of dasatinib $140 \mathrm{mg}$ once daily versus $70 \mathrm{mg}$ twice daily in patients with chronic myeloid leukemia in accelerated phase resistant or intolerant to imatinib: 15-month median follow-up. Blood. 2009;113(25):6322-6329.

3. Lilly MB, Ottmann OG, Shah NP, et al. Dasatinib $140 \mathrm{mg}$ once daily versus $70 \mathrm{mg}$ twice daily in patients with $\mathrm{Ph}$-positive acute lymphoblastic leukemia who failed imatinib: results from a phase 3 study. Am J Hematol. 2010;85(3):164-170.

4. Saglio G, Hochhaus A, Goh YT, et al. Dasatinib in imatinib-resistant or imatinibintolerant chronic myeloid leukemia in blast phase after 2 years of follow-up in a phase 3 study: efficacy and tolerability of 140 milligrams once daily and 70 milligrams twice daily. Cancer. 2010; 116(16):3852-3861.

5. Gleevec (imatinib) [prescribing information]. East Hanover, NJ: Novartis Pharmaceuticals Corporation; 2017.

6. Tasigna (nilotinib) [prescribing information]. East Hanover, NJ: Novartis Pharmaceuticals Corporation; 2017.

7. Porkka K, Khoury HJ, Paquette RL, Matloub Y, Sinha R, Cortes JE. Dasatinib $100 \mathrm{mg}$ once daily minimizes the occurrence of pleural effusion in patients with chronic myeloid leukemia in chronic phase and efficacy is unaffected in patients who develop pleural effusion. Cancer. 2010; 116(2):377-386.

8. Mustjoki S, Ekblom M, Arstila TP, et al. Clonal expansion of T/NK-cells during tyrosine kinase inhibitor dasatinib therapy. Leukemia. 2009;23(8):1398-1405.

9. Agrawal V, Doelken P, Sahn SA. Pleural fluid analysis in chylous pleural effusion. Chest. 2008;133(6):1436-1441.

10. Quintas-Cardama A, Kantarjian H, O'Brien $S$, et al. Pleural effusion in patients with chronic myelogenous leukemia treated with dasatinib after imatinib failure. J Clin
Oncol. 2007;25(25):3908-3914

11. Buettner R, Mesa T, Vultur A, Lee F, Jove R. Inhibition of Src family kinases with dasatinib blocks migration and invasion of human melanoma cells. Mol Cancer Res. 2008;6(11):1766-1774.

12. Wang X, Roy A, Hochhaus A, Kantarjian HM, Chen T-T, Shah NP. Differential effects of dosing regimen on the safety and efficacy of dasatinib: retrospective exposure-response analysis of a Phase III study. Clin Pharmacol. 2013;5:85-97.

13. Conchon M, Freitas CM, Rego MA, Braga Junior JW. Dasatinib-clinical trials and management of adverse events in imatinib resistant/intolerant chronic myeloid leukemia. Rev Bras Hematol Hemoter. 2011;33(2):131-139.

14. de Lavallade $H$, Punnialingam S, Milojkovic $D$, et al. Pleural effusions in patients with chronic myeloid leukaemia treated with dasatinib may have an immune-mediated pathogenesis. Br J Haematol. 2008; 141(5): 745-747.

15. Wang X, Roy A, Hochhaus A, Kantarjian HM, Chen TT, Shah NP. Differential effects of dosing regimen on the safety and efficacy of dasatinib: retrospective exposureresponse analysis of phase III study. Clin Pharmacol. 2013;10(5):85-97

16. Kantarjian H, Shah NP, Hochhaus A, et al. Dasatinib versus imatinib in newly diagnosed chronic-phase chronic myeloid leukemia. N Engl J Med. 2010; 362(24):2260-2270

17. Kantarjian HM, Shah NP, Cortes JE, et al. Dasatinib or imatinib in newly diagnosed chronic-phase chronic myeloid leukemia: 2-year follow-up from a randomized phase 3 trial (DASISION). Blood. 2012; 119(5):1123-1129.

18. Jabbour E, Kantarjian HM, Saglio G, et al. Early response with dasatinib or imatinib in chronic myeloid leukemia: 3-year followup from a randomized phase 3 trial (DASISION). Blood. 2014;123(4):494-500.

19. Cortes JE, Saglio G, Kantariian HM, et al. Final 5-year study results of DASISION: the Dasatinib Versus Imatinib Study in Treatment-Naive Chronic Myeloid Leukemia Patients Trial. J Clin Oncol.
2016;34(20):2333-2340

20. Shah NP, Guilhot F, Cortes JE, et al. Longterm outcome with dasatinib after imatinib failure in chronic-phase chronic myeloid leukemia: follow-up of a phase 3 study. Blood. 2014;123(15):2317-2324

21. Shah NP, Kantarjian HM, Kim DW, et al. Intermittent target inhibition with dasatinib $100 \mathrm{mg}$ once daily preserves efficacy and improves tolerability in imatinib-resistant and -intolerant chronic-phase chronic myeloid leukemia. J Clin Oncol. 2008;26(19):3204-3212.

22. Shah NP, Kim DW, Kantariian $\mathrm{H}$, et al Potent, transient inhibition of BCR-ABL with dasatinib $100 \mathrm{mg}$ daily achieves rapid and durable cytogenetic responses and high transformation-free survival rates in chronic phase chronic myeloid leukemia patients with resistance, suboptimal response or intolerance to imatinib. Haematologica. 2010;95(2):232-240

23. Shah NP, Rousselot P, Schiffer CA, et al. Dasatinib in imatinib-resistant or -intolerant chronic-phase, chronic myeloid leukemia patients: 7-year follow-up of study CA180-034. Am J Hematol. 2016; 91(9):869-874.

24. Saglio G, le Coutre P, Cortes I, et al. Safety and tolerability of dasatinib in patients with chronic myeloid leukemia (CML) and Philadelphia chromosome-positive acute lymphoblastic leukemia (Ph+ ALL): pooled analysis of over 2400 patients. Haematologica. 2014:99(suppl); abstr P884.

25. Guilhot F, Apperley J, Kim DW, et al. Dasatinib induces significant hematologic and cytogenetic responses in patients with imatinib-resistant or -intolerant chronic myeloid leukemia in accelerated phase. Blood. 2007;109(10):4143-4150.

26. Cortes J, Rousselot P, Kim DW, et al. Dasatinib induces complete hematologic and cytogenetic responses in patients with imatinib-resistant or -intolerant chronic myeloid leukemia in blast crisis. Blood. 2007:109(8):3207-3213

27. Hochhaus A, Kantarjian HM, Baccarani M, et al. Dasatinib induces notable hematologic and cytogenetic responses in chronicphase chronic myeloid leukemia after fail- 
ure of imatinib therapy. Blood. 2007; 109(6):2303-2309.

28. Kantarian H, Pasquini R, Hamerschlak N, et al. Dasatinib or high-dose imatinib for chronic-phase chronic myeloid leukemia after failure of first-line imatinib: a randomized phase 2 trial. Blood. 2007;109(12): 5143-5150.

29. Dasatinib in Imatinib Resistant/Intolerant Chinese CML (Chronic and Advanced Phase) Subjects. [clinicaltrials. gov identifier: NCT00529763]. https: //clinicaltrials. gov/ct2/show/NCT00529763?term $=00529$ 763\&rank=1. Accessed October 11, 2017.

30. Trudel GC, Paliwal P, Lainas I. Dasatinib plus SMO antagonist versus dasatinib alone for treating patients (pts) with newly diagnosed Philadelphia chromosome-positive $(\mathrm{Ph}+)$ chronic myeloid leukemia in chronic phase (CML-CP): design of CA180-363, a phase II open-label randomized trial. J Clin Oncol. 2012;20(15 suppl):abstr TSP6634.

31. Talpaz M, Shah NP, Kantariian H, et al. Dasatinib in imatinib-resistant Philadelphia chromosome-positive leukemias. N Engl J Med. 2006;354(24):2531-2541

32. National Cancer Institute. Common Terminology Criteria for Adverse Events (CTCAE) 3.0; $2006 . \quad$ https:// ctep.cancer.gov/protocolDevelopment/elec tronic_applications/docs/ctcaev3.pdf Accessed May 11, 2016

33. Bergeron A, Rea D, Levy V, et al. Lung abnormalities after dasatinib treatment for chronic myeloid leukemia: a case series. Am J Respir Crit Care Med. 2007; 176(8):814-818.

34. Cortes JE, Jimenez CA, Mauro $M$, et al Pleural effusion in dasatinib-treated patients with chronic myeloid leukemia in chronic phase: identification and management. Clin Lymphoma Myeloma. 2017; 17(2):78-82.

35. Schiffer CA, Cortes J, Saglio G, et al. The association of dasatinib-induced lymphocytosis with treatment outcome in patients with chronic myeloid leukemia (CML). Blood. 2013;122(21):2741.

36. La Rosée P, Martiat P, Leitner A, et al.
Improved tolerability by a modified intermittent treatment schedule of dasatinib for patients with chronic myeloid leukemia resistant or intolerant to imatinib. Ann Hematol. 2013;92(10):1345-1350.

37. Cortes J, Hochhaus A, Kantarjian H, et al Impact of dose reductions on 5-year efficacy in newly diagnosed patients with chronic myeloid leukemia in chronic phase (CML-CP) from DASISION. Presented at the American Society of Clinical Oncology 2017 Annual Meeting; June 2-6, 2017; Chicago, IL.

38. Santos FP, Kantariian H, Fava C, et al Clinical impact of dose reductions and interruptions of second-generation tyrosine kinase inhibitors in patients with chronic myeloid leukaemia. Br J Haematol. 2010 150(3):303-312.

39. Iurlo A, Galimberti S, Abruzzese E, et al. Pleural effusion and molecular response in dasatinib-treated chronic myeloid leukemia patients in a real-life Italian multicenter series. Ann Hematol. 2018;97(1):95-100. 